\title{
O TRABALHO EM MARX COMO ANTINATURALIDADE: SOBRE A OPOSIÇÃO ENTRE HISTÓRIA E NATUREZA
}

\author{
Labor in Marx as antinaturality: on the opposition between History and Nature
}

Vitor Vasconcelos de Araújo*

Resumo: Este artigo tem como objetivo apresentar a forma do trabalho em Marx como oposição à dimensão vital da natureza organizada. Discutiremos em $O$ capital a aparição da categoria trabalho como uma forma de transformação dos objetos físicos e naturais a partir do investimento de valor social nas formas imediatas da subsistência nativa dos objetos naturais. Em seguida, mostraremos que a apresentação marxiana se distingue da aparição da vida orgânica no pensamento de Hegel. Com essa apresentação, desejamos mostrar, sobretudo, que para Hegel, a dimensão vital dos organismos vivos já configura uma forma mediata e sucessiva à mecânica e à física. Por esta razão, não pode haver, em Hegel, uma caracterização imediata da natureza na totalidade do sistema. A natureza só pode ser caracterizada como uma imediatez nos Princípios da Filosofia do Direito, com a importante ressalva de que essa imediaticidade é relativa ao Espírito e se apresenta muito mais como uma estratégia de discussão dos objetivos centrais desta obra do que a tentativa de imputar à natureza uma oposição em relação à vida espiritual. Concluímos, portanto, que Marx está mais próximo da restrição metodológica construída por Hegel para discutir a liberdade humana na sua filosofia do direito do que da totalidade construída no conjunto da Enciclopédia.

Palavras-chave: Trabalho. Natureza. Hegel. Marx. Antinatural.
Abstract: This article aims to present the form of labor in Marx as opposed to the vital dimension of organized nature. We will discuss in the Capital the appearance of the category of labor as a form of transformation of the physical and natural objects upon the investment of social value in the immediate forms of native existence of natural objects. Then we will show that the Marxian presentation can be distinguished from the appearance of organic life in Hegel's thought. With this presentation, we want to show, above all, for Hegel, that the vital dimension of living organisms already entails a mediate and successive form of being in relation to mechanical and physical world. For this reason, there cannot be, in Hegel an immediate characterization of the nature within his entire system. Nature can only be described as immediacy in the Principles of philosophy of Right, with the important caveat that this immediacy is on relation to the Spirit and appears much more as a strategy to discuss the central objectives of this work than as an opposition in relation to the spiritual life. We therefore conclude that Marx is closer to the methodological restriction built by Hegel to discuss human freedom in its philosophy of right than to the totality built within the Encyclopedia.

Keywords: Labor. Nature. Antinatural. Hegel. Marx.

*Doutorando pelo Programa de Pós-graduação em Filosofia da Pontifícia Universidade Católica do Rio Grande do Sul e Mestre em Filosofia pela Universidade Federal do Ceará. Contato: vasconcelosvitor@yahoo.com.br

\begin{tabular}{|c|c|c|c|c|r|}
\hline Intuitio & $\begin{array}{c}\text { ISSN } \\
1983-4012\end{array}$ & Porto Alegre & Vol.9- No.2 & $\begin{array}{c}\text { Dezembro } \\
2016\end{array}$ & pp. 103-117 \\
\hline
\end{tabular}




\section{Introdução}

O objetivo deste artigo é tratar o problema do trabalho na filosofia dialética. Em Marx, há uma diferença fundamental nas formas de discussão, na apresentação das determinações da mercadoria, entre natureza e cultura. Nossa intenção é a de apresentar, brevemente, o conceito do trabalho, em Marx, na sua obra magna, O capital, encontrando alguns índices que parecem nos apontar para a produção de uma antropologia econômica. Em seguida, seguimos para a filosofia de Hegel, procurando investigar se o pensamento dialético pode admitir tal dualidade entre natureza e espírito, na medida em que o filósofo dialético alemão se propôs a demonstrar, desde o prefácio da Fenomenologia do espírito, a insuficiência do pensamento a priori e das dualidades não conciliáveis situadas nas antinomias da razão pura. A consciência e a possibilidade de produção das figuras do absoluto, como forma de refutação do ceticismo, aparecem em Hegel como um princípio demonstrado e não como um pressuposto. Com efeito, a aparição da verdade só pode aparecer como o resultado do pensamento e da dissolução de sua lógica interna, na constante posição e pressuposição de categorias que irão produzir o espírito absoluto. Tendo isto como horizonte, seria conceitualmente viável, de acordo com a dialética, a aparição de um princípio antrópico na filosofia econômica de Marx?

Macherey ${ }^{1}$ coloca uma questão importante no diagnóstico do materialismo dialético, cuja origem surge a partir do marxismo soviético: é possível pôr o materialismo sob a forma da dialética? A fenomenologia, a filosofia da natureza e a filosofia do espírito, em suas devidas hierarquias conceituais, não seriam a resposta hegeliana e a indiferença ante a questão do debate materialismo versus idealismo?

\section{A definição do trabalho em Marx}

Para Marx, a categoria de trabalho está intimamente ligada à produtividade de uma forma de subsistência material que não pode existir na natureza por outra forma senão através das técnicas de transformação da realidade imediata do ambiente pelo homem. A atividade produtiva humana é "uma condição de existência do homem, independente de todas as formas sociais, eterna necessidade natural de mediação do metabolismo entre homem e natureza”2 e, ao mesmo tempo, uma especificidade da vida humana, dependente das relações sociais. Portanto, existe um aspecto duplo, uma das primeiras determinações do caráter geminado da mercadoria: de um lado, um produto fabricado através das formas

${ }^{1}$ MACHEREY, P. In a materialist way. In: MONTEFIORE, A. (org). Philosophy in France today. New York: Cambride University Press, 1987.

${ }^{2}$ MARX, K. O capital - volume I. trad. Rubens Enderle. São Paulo: Boitempo, 2013. p.163.

\begin{tabular}{|c|c|c|c|c|c|}
\hline Intuitio & $\begin{array}{c}\text { ISSN } \\
1983-4012\end{array}$ & Porto Alegre & Vol.9- $\mathrm{N}^{\circ} .2$ & $\begin{array}{c}\text { Dezembro } \\
2016\end{array}$ & pp. 103-117 \\
\hline
\end{tabular}


do trabalho humano, de outro, a matéria natural que serve de objeto ao conjunto de técnicas que a transforma em uma mercadoria revestida de valor social.

É através do revestimento de um valor social que a mercadoria pode deixar de ser apenas uma forma de subsistência inerte, passando a entrar em um circuito complexo, capaz de resgatar a matéria bruta da natureza de seu estado nativo e imprimir-lhe um predicado que não pode ser encontrado nas formas imediatas de harmonia com o meio natural. Assim, "é apenas uma relação social determinada entre os próprios homens que aqui assume, para eles, a forma fantasmagórica de uma relação entre coisas”3. Por esta razão, as categorias da troca simples imediatas nos levam até à apresentação dos sistemas de troca complexos a partir de uma relação entre um equivalente universal e um produto de uma quantidade de trabalho socialmente aceita, a mercadoria passa a ser inserida, de forma paulatina, em um circuito de mediação que compõe um sistema de relação que se sobrepõe à imediaticidade da produção, não só da forma de assimilação humana de uma matéria natural, mas também como parte de um circuito no qual a forma dinheiro e não mais a forma mercadoria constitui a finalidade do processo de troca.

Com efeito,

A fim de exercer praticamente o efeito de um valor de troca, a mercadoria tem de se despojar de seu corpo natural, transformando-se de ouro apenas representado em ouro real, mesmo que essa transubstanciação possa ser-lhe mais "amarga” do que o é, para o "conceito" hegeliano, a transição da necessidade à liberdade, ou para uma lagosta a perfuração de sua couraça, ou para São Jerônimo a supressão do velho Adão ${ }^{4}$.

Essa ultrapassagem do grau imediato da transformação do meio natural é tão radical a ponto de produzir uma relação de excesso que constitui o processo mesmo de acumulação da forma dinheiro.

Marx irá demonstrar, em primeiro lugar, que as trocas entre mercadorias, quando saem da sua forma imediata natural, são realizadas graças à mediação do dinheiro. $\mathrm{O}$ vendedor põe no circuito da troca um produto que possui valor de uso para outrem, recebe a forma de equivalência monetária e a troca por outra mercadoria com valor de uso para si. O ciclo da moeda, neste primeiro momento, se fecha com a aquisição do produto através de um montante de equivalente monetário. Contudo, o capital apresenta uma mudança substantiva ou, ainda, apresenta uma propriedade de transubstacialização que produz um circuito tautológico, ultrapassando a esfera da circulação das mercadorias e passa a tornar-se a mercadoria oficial dos contratos.

Tudo se passa como se no primeiro processo a finalidade fosse a troca de uma mercadoria por outra através da mediação de uma forma de equivalência universal, isto é, que era ambiguamente investida de um valor de uso e, ao mesmo tempo, de um valor de troca capaz de ser colocada em um circuito mais abrangente do que as formas primitivas da troca natural. Assim, a equivalência monetária deve estar

\footnotetext{
${ }^{3}$ MARX, K. O capital - volume I. trad. Rubens Enderle. São Paulo: Boitempo, 2013, p. 206.

${ }^{4}$ MARX, K. O capital - volume I. trad. Rubens Enderle. São Paulo: Boitempo, 2013, p.239.
}

\begin{tabular}{|c|c|l|l|c|c|}
\hline Intuitio & $\begin{array}{c}\text { ISSN } \\
1983-4012\end{array}$ & Porto Alegre & Vol.9- $\mathrm{N}^{\mathrm{o} .2}$ & $\begin{array}{c}\text { Dezembro } \\
2016\end{array}$ & pp. 103-117 \\
\hline
\end{tabular}


condicionada ao quanto de absorção ela é capaz de imputar à circularidade dos sistemas de troca, na medida em que a saída de uma forma de troca de equivalência significa, necessariamente, a sua saída e sua substituição por uma mercadoria que possui um valor de uso para o comprador.

A radicalização da relação que sucede a relação M-D-M, isto é, mercadoria-dinheiro-mercadoria, apaga as distinções entre quantidade e qualidade do valor de equivalência universal capaz de produzir um circuito de repetição indefinida que torna o dinheiro a finalidade da circularidade que compõe a troca de dinheiro por uma mercadoria com valor de uso.

A forma M-D-M é ultrapassada por outra mediação, capaz de complexificar ainda mais a já elaborada estrutura entre o comprador e o vendedor não contida nas formas naturais dos sistemas de troca. Daí, "a venda deixa de ser suplementada pela compra subsequente" 5 e a mercadoria passa a não ser a finalidade do aparecimento da forma de equivalência universal do papel dinheiro, mas são coadjuvantes de uma infinitude improdutiva, na qual repete-se as relações entre compradores e vendedores com a finalidade de produzir, ao final da transação, o acúmulo e o débito. O vendedor pode passar, por conta desse processo, da condição de um vendedor para um entesourador.

O ouro e a prata se tornam, por si mesmos, expressões sociais da superfluidade ou da riqueza. Essa forma ingênua de entesouramento se eterniza em povos em que o modo de produção tradicional e orientado à autossubsistência corresponde a um círculo rigidamente fechado de necessidades ${ }^{6}$.

Portanto, em síntese, temos o seguinte processo: em primeiro lugar, a simplicidade da imediaticidade das relações entre mercadorias, a forma $\mathrm{M}-\mathrm{M}$, na qual a forma natural é o condicionante dos sistemas de troca realizados entre as matérias produzidas e as necessidades de uso. Marx utiliza a figura de Robinson Crusoé ${ }^{7}$ para ilustrar a simplicidade do circuito que é produzido a partir das necessidades naturais internas entre um indivíduo naufragado e o caráter quase natural de seus sistemas de troca. Mesmo pertencendo à cultura cosmopolita que envolve a produção e o desenvolvimento de um aparato técnico, uma dimensão concreta da produção que envolve a transformação de galhos em utensílios, madeira de árvore em uma cabana e as folhas em alimento para o fogo, o fator social não se encontra presente, e, portanto, a mercadoria não possui uma determinação importante ao processo de apresentação que irá desembocar no nascimento do capital: seu aspecto abstrato. Isto não significa dizer que o aspecto abstrato configura um tipo de determinação irreal, uma vez que as relações entre os homens produzem uma efetividade não-concreta, mas de efeitos duramente reais. Significa dizer que o aspecto abstrato da mercadoria, inserido dentro de um conjunto de trocas sociais, situa a mercadoria através de determinações que fazem com que seu acesso seja mediado a partir da relação que ela possui, juntamente

\footnotetext{
${ }^{5}$ MARX, K. O capital - volume I. trad. Rubens Enderle. São Paulo: Boitempo, 2013, p. 272.

${ }^{6}$ MARX, K. O capital - volume I. trad. Rubens Enderle. São Paulo: Boitempo, 2013, p. 271-272

${ }^{7}$ MARX, K. O capital - volume I. trad. Rubens Enderle. São Paulo: Boitempo, 2013, p. 211.
}

\begin{tabular}{|c|c|l|l|c|c|}
\hline Intuitio & $\begin{array}{c}\text { ISSN } \\
1983-4012\end{array}$ & Porto Alegre & Vol.9- No.2 & $\begin{array}{c}\text { Dezembro } \\
2016\end{array}$ & pp. 103-117 \\
\hline
\end{tabular}


com os valores de uso, com o aspecto elaborado de seus valores de troca, não aplicável à particularidade do homem selvagem, e, finalmente, com o valor de trabalho imputado à produção da mercadoria, dentro de um conjunto de signos sociais que condicionam o valor da mercadoria de acordo com propriedades, por assim dizer, sintéticas, isto é, que não estão contidas, analiticamente, no interior da apresentação imediata e natural da mercadoria.

Daí se segue uma segunda mudança qualitativa que produz um valor socialmente aceito de trabalho, inserindo a mercadoria em um circuito social que a situa através da mediação de um sistema de equivalência universal em relação à outra mercadoria. Equivalente universal que possui, ao mesmo tempo, valor de troca e valor de uso. Assim, a mercadoria está condicionada, no reconhecimento de seu aspecto qualitativo, mas também quantitativo, que assegura na equação das trocas a presença das variáveis de sua absorção no interior de um sistema econômico.

A partir desse momento, os trabalhos privados dos produtores assumem, de fato, um duplo caráter social. Por um lado, como trabalhos úteis determinados, eles têm de satisfazer uma determinada necessidade social e, desse modo, conservar a si mesmos como elos do trabalho total, do sistema natural-espontâneo da divisão social do trabalho. Por outro lado, eles só satisfazem as múltiplas necessidades de seus próprios produtores na medida em que cada trabalho privado e útil particular é permutável por qualquer outro tipo útil de trabalho privado, portanto, na medida em que lhe é equivalente ${ }^{8}$.

Uma forma ainda, portanto, ligada a certas condições naturais que "baseia-se em relações de produção que se reproduzem com a imutabilidade de condições naturais, aquela forma de pagamento conserva retroativamente a antiga forma de produção"’.

Daí produz-se, em decorrência do modelo anterior, a forma sucessiva D-M-D, isto é, dinheiromercadoria-dinheiro, na qual produz mais uma camada de mediação à circulação monetária. Esta novidade desconhece a distinção entre os aspectos quantitativos e qualitativos da equivalência universal e torna-se tão somente uma forma tautológica de acumulação de dinheiro, ao invés de constituir-se a partir de uma contradição, aparentemente, resolvida da forma M-D-M. Esta que possuía o dinheiro como a mediação para se atingir a finalidade de troca de mercadorias. Ao contrário, no caso da forma D-M-D, a mercadoria é a mediação para que se possa atingir a forma da acumulação do capital.

O que temos desta pequena síntese, que nos leva da produção das trocas simples ao nascimento do capital, é a insistência de Marx de que o modo natural de disposição das matérias da natureza não justifica por si a complexidade das mudanças da qualidade das trocas e, portanto, do aparecimento do acúmulo da forma dinheiro. A natureza é, decerto, um aspecto importante, pois ela é responsável por nos fornecer um grau de determinação biológica encontrada na naturalidade da execução do trabalho, porém insuficiente, pois precisa ser superada, de modo a ser capaz de produzir formas mediatas da troca da

\footnotetext{
${ }^{8}$ MARX, K. O capital - volume I. trad. Rubens Enderle. São Paulo: Boitempo, 2013, p. 208.

${ }^{9}$ MARX, K. O capital - volume I. trad. Rubens Enderle. São Paulo: Boitempo, 2013, p. 283.
}

\begin{tabular}{|c|c|l|l|c|c|}
\hline Intuitio & $\begin{array}{c}\text { ISSN } \\
1983-4012\end{array}$ & Porto Alegre & Vol.9- $\mathrm{N}^{\mathrm{o} .2}$ & $\begin{array}{c}\text { Dezembro } \\
2016\end{array}$ & pp. 103-117 \\
\hline
\end{tabular}


mercadoria, ao invés de manter-se como um sistema simples capaz de fornecer somente uma forma de troca de equivalência de 1 a 1 em um meio animal ou em um meio humano não social.

Marx, certamente, obedece a um princípio de determinação relacional que encontramos na dialética de Hegel, na medida em que a apresentação da constituição da forma dinheiro nos apresenta, frequentemente, oposições, que quando superadas, dão início a novas oposições qualitativamente distintas das contradições anteriores. Assim, para a determinação dos processos que levam da matéria natural até a socialização dos meios produtivos, passando pelo desenvolvimento das forças de trabalho, é preciso reconhecer, a presença da natureza no nascimento das formas primitivas de transformação da matéria inerte do ambiente natural.

Entretanto, devemos ser capazes de colocar um problema na descrição até agora mostrada por Marx, porquanto parece negligenciar o aspecto mediato encontrado anteriormente às formas da sociabilidade humana. Assim, é inteiramente questionável a tendência natural das matérias nativas de permanecerem imediatamente disponíveis para o uso, ou ainda, de supor apenas nas formas da sociabilidade humana a capacidade de retirar os objetos naturais de sua imediatez, imprimindo-lhes a força da produção, que contém, por sua vez, não só um valor de uso para si, mas para outrem. Com efeito, a inclusão das formas de equivalência realiza, idealmente, para Marx, a recusa da disposição material da natureza, que só podem entrar no mundo humano desde que seja transformada de acordo com suas finalidades do trabalho antrópico.

Por isso, a partir das próprias palavras de Marx, um animal diferencia-se do homem na medida em que a quantidade de trabalho exercida para a realização de uma finalidade, no primeiro caso, é exatamente proporcional à quantidade de tarefa realizada pelo organismo vivo.

No final do processo de trabalho, chega-se a um resultado que já estava presente na representação do trabalhador no início do processo, portanto, um resultado que já existia idealmente. Isso não significa que ele se limite a uma alteração da forma do elemento natural; ele realiza neste último, ao mesmo tempo, seu objetivo, que ele sabe que determina, como lei, o tipo e o modo de sua atividade e ao qual ele tem de subordinar sua vontade ${ }^{10}$.

Com efeito, a relação entre ação e potência no animal esgota, ao fim da realização da finalidade, a representação do trabalho imputado à realidade material da natureza, ao passo que no homem, há uma cisão entre atualidade e a possibilidade do trabalho, no qual este exerce sempre uma quantidade menor ou maior de trabalho para a realização de um produto. Exatamente por constituir uma insubordinação à finalidades já prontas, a atividade humana é capaz de, retroativamente, possuir uma história, uma vez que não se põe a seguir os passos determinados pela natureza exterior.

Um produto que serve imediatamente a partir de um valor de uso da alimentação, como a uva, por exemplo, pode adentrar, na história da humanidade, em um circuito que confere ao alimento diversas

${ }^{10}$ MARX, K. O capital - volume I. trad. Rubens Enderle. São Paulo: Boitempo, 2013, p. 237.

\begin{tabular}{|c|c|c|c|c|c|}
\hline Intuitio & $\begin{array}{c}\text { ISSN } \\
1983-4012\end{array}$ & Porto Alegre & Vol.9- $\mathrm{N}^{\circ} .2$ & $\begin{array}{c}\text { Dezembro } \\
2016\end{array}$ & pp. 103-117 \\
\hline
\end{tabular}


finalidades possíveis: produção de vinagre, do vinho, de alimento para animais de corte, ou ainda, de adubo, etc. O animal, ao contrário da pluralidade das finalidades produtivas humanas, estaria condicionado, tão somente pelas formas imóveis do trabalho imediato para o qual as formas instintivas imediatamente se realizam na natureza.

Para Engels (1968), seguindo a mesma linha argumentativa marxiana,

Os animais também [apresentam ferramentas] no sentido estrito da palavra: a formiga, a abelha, o castor, que têm ferramentas, mas eles são apenas os membros do seu corpo; os animais também são produtores, mas o seu efeito produtivo sobre a natureza circundante é praticamente nulo em termos de natureza. Só o homem conseguiu imprimir seu selo na natureza, não só mudando o mundo vegetal e animal, mas também transformar seu o aspecto - o clima de suas casas, mesmo os animais e plantas, e isto aponta que as consequências de sua atividade só podem desaparecer com o declínio geral da terra ${ }^{11}$.

Para Engels, as atividades animais se perdem no tempo, enquanto que as atividades humanas são capazes de imputar à história do mundo a indestrutibilidade de suas ações. Ou seja, são capazes de ultrapassar a tautologia entre reprodução e morte, emulando sua interioridade na exterioridade do mundo a partir das formas objetivas da cultura. Portanto, os fatos da anatomia comparada, juntamente com o apoio nas teorias da história da evolução das espécies, nos mostram que esta extraordinária capacidade se deve pelo fato da postura ereta e da liberação das mãos por parte dos ancestrais da rede evolutiva que tornou possível a aparição do homem, que deixam de exercer funções de locomoção e passam a manipular os objetos. Esse salto evolutivo, juntamente com o surgimento de um cérebro robusto, é a justificativa material para o aparecimento dos comportamentos humanos e de suas distinções para com os animais.

Ao fim, temos uma ampliação da função da categoria de trabalho, em Marx e em Engles, que “é paga, entre outras coisas, com a necessidade de distinção ontológica entre expressão subjetiva e comportamento natural” ${ }^{12}$.

Parece haver, inclusive em Marx, na distinção entre as ideias de abstração e idealidade, uma tese que reforça nossa argumentação. Enquanto as primeiras são uma síntese da oposição entre o trabalho concreto (técnicas, instrumentos de manipulação, as próprias determinações anatômicas da corporeidade humana) e o trabalho abstrato (o circuito não-concreto, porém, objetivo das mediações sociais que revestem a matéria natural), as segundas, as ideias de idealidade, são a realização, em animais, da perfeita sincronia de trabalho investido em uma atividade objetiva, de modo a não produzir excessos produtivos. Uma abelha exerceria uma quantidade de trabalho exatamente proporcional à quantidade de mel que deseja produzir, ao passo que o homem excede o trabalho necessário para a produção de uma mercadoria. Por isso, no primeiro caso, a abelha é ideal porquanto contém uma representação de trabalho adequada à finalidade de sua tarefa, enquanto no homem, a quantidade de trabalho investida na realização de uma

${ }^{11}$ ENGELS, F. Dialectique de la nature. Paris: Édition sociale, 1968, p. 31

${ }^{12}$ SAFATLE, V. Circuito dos afetos: corpos políticos, desamparo e o fim do indivíduo. São Paulo: Cosac Naify, 2015, p. 243.

\begin{tabular}{|c|c|l|l|c|c|}
\hline Intuitio & $\begin{array}{c}\text { ISSN } \\
1983-4012\end{array}$ & Porto Alegre & Vol.9- N $^{\circ} .2$ & $\begin{array}{c}\text { Dezembro } \\
2016\end{array}$ & pp. 103-117 \\
\hline
\end{tabular}


atividade sempre sofre de um excesso. Isto explica, no segundo caso, ao menos, o princípio de acúmulo de riquezas.

Contudo, temos outra forma de olhar para esse fato, ou seja, para a distinção entre homens e animais. Se voltarmos à filosofia da natureza de Hegel, veremos que o mundo natural não é simplesmente negado pelo mundo da cultura humana, como Marx e Engels parecem nos indicar. Isto é, a natureza não é somente pressuposta na filosofia da cultura humana, pois não se trata de um tipo de pressuposição, na qual um a priori é linearmente condicionante de sua contraparte empírica, mas de uma circularidade que pressupõe e é pressuposta mutuamente. Assim, a realidade natural dá-se não só como uma pressuposição da vida espiritual, mas também a vida espiritual já se encontra pressuposta na natureza. Por isso, o mundo animal não é uma mera convenção à substancialidade dos materiais de seu meio. Os animais, assim como os homens, apresentam um nível de idealidade capaz de recusar a imediatez do Ser para transformá-lo de acordo com um princípio de coerência interna. Como nos mostra Hegel, a chegada da ideia às formas orgânicas, implica em uma passagem pela mecânica e pela física. Portanto, a natureza viva não humana já é duplamente mediada.

\section{O caráter mediato da filosofia da natureza viva}

Por isso, Hegel é capaz de afirmar que “a ideia da vida é, nela, este algo criativo incônscio - uma expansão da natureza que no vivente voltou a sua verdade”13. Assim, a primeira forma do idealismo contida no mundo animal consiste na capacidade dos organismos vivos de "pôr o exterior como subjetivo, antes de tudo fazer sê-lo ele próprio, identifica-lo consigo, isto é, o assimilar" ${ }^{14}$.

O cheiro e o gosto, por exemplo, são uma aparição de um princípio de reflexividade na qual o objeto de assimilação é o real ser das coisas e através dos quais a realidade exterior é consumida e trazida para a interioridade. De forma geral, “o idealismo começa disto que nada em geral pode ter com o ser vivo uma relação positiva cuja possibilidade não fosse este [ser] em si e por si mesmo, isto [relação positiva] que não fosse determinada pelo conceito, com isto meramente imanente ao sujeito” ${ }^{15}$. Assim, o animal reestabelece a conciliação contida na falta como impulso que se põe a realizar sua interioridade exteriormente, através do apetite animal no qual as formas não-humanas de vida "estabelecem de novo a

\footnotetext{
${ }^{13}$ HEGEL, G.W.F. Enciclopédia das ciências filosóficas, v. II. A filosofia da natureza. São Paulo: Edições Loyola, 1997, p. 483.

${ }^{14}$ HEGEL, G.W.F. Enciclopédia das ciências filosóficas, v. II. A filosofia da natureza. São Paulo: Edições Loyola, 1997, p. 484.

${ }^{15}$ HEGEL, G.W.F. Enciclopédia das ciências filosóficas, v. II. A filosofia da natureza. São Paulo: Edições Loyola, 1997, p. 488.
}

\begin{tabular}{|c|c|c|c|c|c|}
\hline Intuitio & $\begin{array}{c}\text { ISSN } \\
1983-4012\end{array}$ & Porto Alegre & Vol.9- $\mathrm{N}^{\circ} .2$ & $\begin{array}{c}\text { Dezembro } \\
2016\end{array}$ & pp. 103-117 \\
\hline
\end{tabular}


O Trabalho em Marx como Antinaturalidade: sobre a oposição entre história e natureza

paz e se satisfaz em si” ${ }^{16}$. Daí porque o desejo animal, a pulsão instintiva, é a tentativa de suprassumir a falta, presente somente nas formas superiores de vida, produzindo, uma forma interna que não se reduz somente a um elemento subjetivo, projetando-se na objetividade. Com efeito, o instinto animal é uma maneira de agência de acordo com propósitos internos, com a ressalva de que elas operam nos animais de modo inconsciente, pois ainda não estamos na filosofia do espírito, embora esta seja o princípio espiritual da vida animal, e, ao mesmo tempo, a naturalidade da autoconsciência humana, que se faz presente através das narrativas históricas ${ }^{17}$.

Por isso, Hegel afirmará que o processo do nascimento da idealidade na vida animal tem limites claros, dada a maneira estreita com a qual os animais são capazes de reagir a conjuntos distintos de suas prescrições instintivas. Isto é, são sensíveis apenas a uma forma (Gestalt) definida de estimulações para as quais o instinto prescreve o modo de ação, mesmo que esta seja, como Hegel afirmou anteriormente, internamente assimilada de acordo com a exterioridade objetiva ${ }^{18}$.

Finalmente, "a vida, o sujeito destes momentos da totalidade, tensiona-se em si como conceito e nos momentos como realidade exterior a ele e é conflito duradouro no qual a vida supera esta exterioridade” ${ }^{19}$, já que o animal determina a partir de uma síntese interna, e de uma vez por todas, os locais onde exerce sua atividade vital. Aí está posta a capacidade prática da Ideia: a de impulsionar, de forma inadvertida ${ }^{20}$, agentes para finalidades que, por razões desconhecidas, eles mesmos delimitam para si.

Em síntese, a permissividade com o externo, "este mesmo deixar entrar, portanto, constitui o objetivo do organismo, que ele tem de superar e digerir. Esta virada do ponto de vista é o princípio da

\footnotetext{
${ }^{16}$ HEGEL, G.W.F. Enciclopédia das ciências filosóficas, v. II. A filosofia da natureza. São Paulo: Edições Loyola, 1997, p. 491.

17 "Povos da terra sentem a marcha da natureza, porém o espírito faz da noite dia; e assim são mais fracas as afinações das estações do ano dentro das organizações superiores”. HEGEL, G.W.F. Enciclopédia das ciências filosóficas, v. II. A filosofia da natureza. São Paulo: Edições Loyola, 1997, p. 493.

${ }^{18}$ Esta premissa se manterá relativamente intacta no pensamento filosófico, encontrando em Uexküll (BIMBENET, E. L'animal que ne je suis plus, Paris: Gallimar, 2011, p. 112-116, HEIDEGGER, M. Fundamental concepts of metaphysics, Indiana: Indiana University Press, 1995, §§ 46 e 47) e o Merleau-Ponty dos anos de 1940 (MERLEAUPONTY, M. A estrutura o comportamento. São Paulo: Martins Fontes, 2006; MERLEAU-PONTY, M. Phénoménologie de la perception. Paris: Gallimard, 1976; MERLEAU-PONTY, M. Conversas - 1948. São Paulo: Martins Fontes, 2004.) uma disseminação da tese de uma insensibilidade animal a estímulos exteriores por parte de suas capacidades instintivas e a impossibilidade da inventividade vital do mundo orgânico.

${ }^{19}$ HEGEL, G.W.F. Enciclopédia das ciências filosóficas, v. II. A filosofia da natureza. São Paulo: Edições Loyola, 1997, p. 494.

20 "Como o animal é sujeito, negatividade simples, então esta assimilação não pode ser nem de natureza mecânica, nem química, já que nestes processos tanto as matérias como as condições e a atividade permanecem exteriores entre si e carecem da unidade vivente absoluta”. HEGEL, G.W.F. Enciclopédia das ciências filosóficas, v. II. A filosofia da natureza. São Paulo: Edições Loyola, 1997, p. 497-498.
}

\begin{tabular}{|c|c|l|l|c|c|}
\hline Intuitio & $\begin{array}{c}\text { ISSN } \\
1983-4012\end{array}$ & Porto Alegre & Vol.9- N $^{\circ} .2$ & $\begin{array}{c}\text { Dezembro } \\
2016\end{array}$ & pp. 103-117 \\
\hline
\end{tabular}


reflexão do organismo sobre si; e o retorno a si é a negação de sua atividade orientada para fora”21, ou ainda, o organismo "é um seu caminhar-junto consigo mesmo no seu processo externo"22.

Segue-se do processo de assimilação, o Kunsttrieb (impulso da arte) que está presente na formação de ninhos, depósitos e covis por animais, de modo a tornar mais confortável sua relação com a exterioridade e forçar na objetividade em-si a unidade inacabada do para-si da ideia ${ }^{23}$. A vida pode, até mesmo, prolongar-se em seu Umwelt, e duplicar a si mesma, estendendo a forma subjetiva interna na exterioridade da natureza. Hegel caracteriza essas produções como uma fruição de si, como no caso da projeção da voz animal, fazendo aparecer uma maneira mais elevada da satisfação primitiva da fome, que se fez somente dentro dos limites da corporeidade interna do animal e que nos cantos dos pássaros pode projetar-se como uma forma de comportamento que cativa a si mesmo. O impulso produtivo faz então com que os animais recebam da natureza exterior a "certeza de si mesmos, ao seu conceito subjetivo, a verdade, objetividade, enquanto indivíduo singular”24. Essa produção é a precipitação do processo reprodutivo, que antevê, no mundo animal, a dialética do reconhecimento humana, isto é, "um impulso de conseguir no outro do seu gênero sua auto-sensação [Selbstegefühl], pela união com ele integrar-se e por meio desta mediação encadear [zussamenzuschliessen] consigo e trazer a existência o gênero - é a cópula [Begattung]"25.

Por isso, a idealidade da auto-sensação se consolida, em um primeiro momento, no animal, através da realização dos propósitos que ele mesmo constrói para si, na assimilação. Em seguida, na reprodução, a reflexividade subjetiva é negada pela presença do gênero oposto, produzindo uma vitalidade autorreferente, isto é, uma volta a si mais universal do que aquela contida na individualidade organísmica, que passa à existência após a cópula. Trata-se de uma reflexividade mais abrangente do que a forma simples da assimilação, porquanto não somente volta a si, mas unifica duas particularidades, gerando outra reflexividade. Para Hegel, “esse sentimento de universalidade é o mais alto a que o animal se pode levar; mas neste sentimento sua universalidade concreta nunca se torna para ele objeto teórico da intuição” ${ }^{26}$. Por esta razão, a forma produtiva se esgota no animal com a sua morte, que perdura em um processo

\footnotetext{
${ }^{21}$ HEGEL, G.W.F. Enciclopédia das ciências filosóficas, v. II. A filosofia da natureza. São Paulo: Edições Loyola, 1997, p. 499.

${ }^{22}$ HEGEL, G.W.F. Enciclopédia das ciências filosóficas, v. II. A filosofia da natureza. São Paulo: Edições Loyola, 1997, p. 501.

${ }^{23}$ HEGEL, G.W.F. Enciclopédia das ciências filosóficas, v. II. A filosofia da natureza. São Paulo: Edições Loyola, 1997, p. 514.

${ }^{24}$ HEGEL, G.W.F. Enciclopédia das ciências filosóficas, v. II. A filosofia da natureza. São Paulo: Edições Loyola, 1997, p. 516.

${ }^{25}$ HEGEL, G.W.F. Enciclopédia das ciências filosóficas, v. II. A filosofia da natureza. São Paulo: Edições Loyola, 1997, p. 534.

${ }^{26}$ HEGEL, G.W.F. Enciclopédia das ciências filosóficas, v. II. A filosofia da natureza. São Paulo: Edições Loyola, 1997, p. 535.
}

\begin{tabular}{|c|c|c|c|c|c|}
\hline Intuitio & $\begin{array}{c}\text { ISSN } \\
1983-4012\end{array}$ & Porto Alegre & Vol.9- $\mathrm{N}^{\circ} .2$ & $\begin{array}{c}\text { Dezembro } \\
2016\end{array}$ & pp. 103-117 \\
\hline
\end{tabular}


tautológico incapaz de superar a integridade da figura singular ${ }^{27}$. Assim, "O ser-para-si suprassumido é a forma do objeto que foi produzido por meio do Si; ou melhor: é o Si produzido, desgastando-se; quer dizer, convertendo-se em coisa. Acima desses espíritos animais que só [se] dilaceram, o artesão mantém sua superioridade; sua ação não é apenas negativa, mas sim tranquila e positiva”28.

Vimos, então, que para Hegel, a vida é, sobretudo, a possibilidade de uma realização de uma interioridade na exterioridade, abandonando o solipsismo e a imediaticidade das formas subjetivas, generalizando a ideia através da posição de um si na objetividade nos processos da assimilação e da reprodução. No entanto, ela se depara com um limite, porquanto é incapaz de subsistir a forma do si para além da morte, onde a particularidade do vivente é passada adiante sem ser possível sua ultrapassagem. Por isso, a ideia deve utilizar como plataforma não mais a repetição incessante entre a reprodução e a morte, mas deve dirigir-se para a inventividade da cultura, capaz de expor na filosofia do espírito, o preenchimento real da atividade de auto-compreensão do espírito absoluto, fundando, ao mesmo tempo, o reconhecimento do homem na história e, mais radicalmente, o seu fim. Através da consciência da morte, o homem dá início ao processo seguinte que busca não somente a perpetuação do si e de sua reprodução, mas fazer a volta reflexiva, fundando, com isso, a autorreferência da ideia, fechando o ciclo no qual o espírito é natureza cônscia de si, e a natureza, por sua vez, espírito alienado de si.

A forma da produção humana, em Hegel, é a única capaz de escapar do circuito tautológico entre reprodução e morte, a partir do exercício de uma reflexividade que o animal jamais poderá conhecer, mas isso não significa que temos no mundo animal um tipo de relação com a natureza a partir de exigências externas. Hegel nos mostra que o interior da filosofia da natureza é a paulatina aproximação da realização reflexiva da ideia e, portanto, tanto mais nos aproximemos de sua relação no espírito, tanto mais chegamos próximos de uma forma de autorealização reflexiva que resiste à produção de finalidades exteriores. A Fenomenologia do espírito nos mostrará que a vida apresenta o aparecimento da consciência-de-si ${ }^{29}$, quando esta é capaz de separar-se e ao mesmo tempo consumir a natureza inorgânica.

Há aqui uma forma correta da posição do problema em Marx: a de que a realidade humana é qualitativamente distinta do trabalho animal. Contudo, as justificações são distintas daquelas encontradas em Hegel. Marx parece caracterizar a realidade animal como uma forma de vida sem intermédios, encontrando exclusivamente na vida humana um conjunto de superposições abstratas que medeiam a relação que possuem nas formas abstratas da troca monetária. Para Hegel, ao contrário, trata-se de

\footnotetext{
27 “A consciência-de-si efetiva desse espírito disperso é uma multidão de espíritos-de-povos, isolados e insociáveis, que em seu ódio se combatem até a morte e se tornam conscientes de figuras animais determinadas como de sua essência, porque não são outra coisa que espíritos animais, vidas animais que se isolam conscientes delas sem universalidade”. HEGEL, G.W.F. Fenomenologia do espírito. Rio de Janeiro: Editora Vozes, 2002, p. 458.

${ }^{28}$ HEGEL, G.W.F. Enciclopédia das ciências filosóficas, v. II. A filosofia da natureza. São Paulo: Edições Loyola, 1997, p. 458.

${ }^{29}$ HEGEL, G.W.F. Fenomenologia do espírito. Rio de Janeiro: Editora Vozes, 2002, p. 138.
}

\begin{tabular}{|c|c|c|c|c|c|}
\hline Intuitio & $\begin{array}{c}\text { ISSN } \\
1983-4012\end{array}$ & Porto Alegre & Vol.9- $\mathrm{N}^{\circ} .2$ & $\begin{array}{c}\text { Dezembro } \\
2016\end{array}$ & pp. 103-117 \\
\hline
\end{tabular}


caracterizar a humanidade como a superação e, ao mesmo tempo, a conservação da natureza, ou melhor, implica em admitir no homem não o fracasso das leis inertes do meio natural, mas uma atualização do poder natural de suas leis no comportamento humano. A espécie humana é, portanto, um evento supernatural, pois impõe ao horizonte normativo do instinto não simplesmente sua negação cultural, mas outro conjunto de normas que os tornam capazes de realizar as finalidades instintivas, ou de recusar a forma da teleologia natural.

Evidentemente, não se trata aqui de retomar as descrições de uma ciência natural, por vezes, ultrapassada na filosofia de Hegel, mas de conservar a sua argumentação central: a de que é impossível do ponto de vista da Lógica (filosofia sistemática), distinguir radicalmente o trabalho humano do comportamento animal. Ou ainda, concluir que o caráter imediato da vida animal se dá em relação à vida espiritual e não em relação à natureza organizada ${ }^{30}$. Na verdade, a distinção é desejável, uma vez que é a partir dela que a tautologia do ser vivo pode libertar-se da sua cegueira espiritual, mas ao mesmo tempo é o enraizamento inescapável da gênese da cultura.

Para Hegel, “Enquanto existência imediata, não é o corpo adequado ao espírito. Para vir a ser um órgão dócil e um instrumento animado, é preciso que seja possuído por ele” ${ }^{11}$ (HEGEL, 1997b, p. 49). Por isso, para que haja liberdade, é preciso haver uma capacidade de apreensão de si por si. Evento que não pode ser testemunhado na natureza, uma vez que nela ainda não há a existência da liberdade. Finalmente, nela existe uma indiferença ao perspectivismo necessário para a produção da justiça e da verdade.

Em conclusão, Marx parece estar mais próximo do Hegel dos Princípios da Filosofia do Direito, onde há o reconhecimento deste da alienação da natureza de si e, portanto, de que o homem, em sua existência imediata, é um ser natural. No entanto, Hegel deixa claro que esse caráter imediato da existência humana é relativo ao objeto de discussão da obra, qual seja, a liberdade, no aparecimento da eticidade objetiva (Sittlichkeit). Isto é, Hegel é capaz de reconhecer a independência do sentido natural no interior da própria natureza, embora a teleologia do mundo orgânico se apresente como uma "harmonia eterna”32, rompida a partir do aspecto contingente do mundo moral. Já na Enciclopédia as diferenças são justificadas ante a sistematicidade da obra na qual é possível observar, na riqueza das determinações do ser natural, uma posição clara na hierarquia dos conceitos. Assim, a natureza viva não é tomada como se fosse uma simples imediaticidade ontológica, porquanto a mecânica, a primeira determinação da filosofia da natureza, deverá ser revestida por formas de mediação relativas que correspondem ao nascimento do mundo químico e do mundo da vida orgânica ${ }^{33}$. Com efeito, o aparecimento da vida natural já é, para

\footnotetext{
${ }^{30}$ HEGEL, G.W.F. Princípios da filosofia do direito. São Paulo: Martins Fontes, 1997, p. 48.

${ }^{31}$ HEGEL, G.W.F. Princípios da filosofia do direito. São Paulo: Martins Fontes, 1997, p. 49.

${ }^{32}$ VITORINO, O. Prefácio à $2^{\circ}$ edição. In: HEGEL, G.W.F. Princípios da filosofia do direito. São Paulo: Martins Fontes, 1997, p. XXVIII.

${ }^{3}$ Parte desta justificativa também se encontra na ultrapassagem da consciência da anatomia do crânio, a frenologia,
}

\begin{tabular}{|c|c|c|c|c|r|}
\hline Intuitio & $\begin{array}{c}\text { ISSN } \\
1983-4012\end{array}$ & Porto Alegre & Vol.9- No.2 & $\begin{array}{c}\text { Dezembro } \\
2016\end{array}$ & pp. 103-117 \\
\hline
\end{tabular}


O Trabalho em Marx como Antinaturalidade: sobre a oposição entre história e natureza

Hegel, uma mediação já longamente constituída pela refutação do princípio da causalidade e da imediaticidade da física clássica.

Com efeito, os Princípios da filosofia do direito de Hegel estão repletos do que parece ser à primeira vista uma apreciação pejorativa do ser natural. Tudo se passa como se Hegel estivesse descrevendo uma filosofia da moralidade que apresenta sua validade a partir das descrições de um conjunto de determinações que encontram no ser natural uma plataforma insuficiente para sua realização. Assim, o mundo da cultura produziria uma propriedade emergente que não encontramos na natureza. Por esta razão, "não se poderia falar de injustiça da natureza [...], pois a natureza não sendo livre, não é justa nem injusta" 34 .

O mundo circundante, para Hegel seria composto de objetos que são entendidos a partir da finalidade a partir da qual são observados pela consciência, uma vez que são condicionados pelo uso que fazemos deles. Por outro lado, a autoridade das leis morais seria "infinitamente mais elevada, pois as coisas naturais só de um modo exterior e isolado apresentam um caráter racional, que, aliás, escondem na aparência da contingência”35. O que Hegel quer dizer com esta nota ao parágrafo 146 da obra é de indicar que existe um princípio autotélico melhor acabado nas formas do espírito. Nestes, a finalidade das leis da moralidade é interna à própria criação dos seus agentes. Ou seja, os objetos criados pelo sujeito moral nascem da sua própria interioridade, enquanto a natureza preserva um princípio externo que não encontra na aparição sua mesma as finalidades de uso.

Daí que é preciso “desbravar a simplicidade da natureza, quer dizer, a passiva privação de si e a incultura do saber e da vontade [...]”36. E por isso mesmo é falsa a acepção na qual é possível assumir, segundo as filosofias românticas, que a perversão da cultura ante o aspecto imaculado da realidade natural é a gênese da infelicidade humana e de que, portanto, à distância dos meios da produção de uma sociedade, o homem estaria liberto das obrigações e constrangimentos dos modos de inscrição na cultura. O elemento da libertação do homem, dirá Hegel, se encontra exatamente a partir da dimensão do trabalho. A partir deste, a espiritualidade deve livrar-se das amarras da natureza e sair do estado de selvageria e nãoliberdade, uma vez que o ser livre "só existe na reflexão espiritual em si mesmo, na sua distinção da natureza e na ação refletida sobre si” $^{37}$. Os dons da corporeidade viva e da espiritualidade são, portanto,

seu aspecto mecânico, a partir do aparecimento do caráter dinâmico e organizado da fisiognomia (Cf. HEGEL, G.W.F. Fenomenologia do espírito. Rio de Janeiro: Editora Vozes, 2002, p. 219-244). A primeira como forma de aparecimento da Coisa imediata e a segunda como a forma mediata da observação de uma individualidade vertical, que possui na visibilidade das expressões da face, uma transparência do invisível (Cf. HEGEL, G.W.F. Fenomenologia do espírito. Rio de Janeiro: Editora Vozes, 2002.p. 226).

${ }^{34}$ HEGEL, G.W.F. Princípios da filosofia do direito. São Paulo: Martins Fontes, 1997, p. 51.

${ }^{35}$ HEGEL, G.W.F. Princípios da filosofia do direito. São Paulo: Martins Fontes, 1997, p. 142.

${ }^{36}$ HEGEL, G.W.F. Princípios da filosofia do direito. São Paulo: Martins Fontes, 1997, p. 171.

${ }^{37}$ HEGEL, G.W.F. Princípios da filosofia do direito. São Paulo: Martins Fontes, 1997, p. 176.

\begin{tabular}{|c|c|l|l|c|c|}
\hline Intuitio & $\begin{array}{c}\text { ISSN } \\
1983-4012\end{array}$ & Porto Alegre & Vol.9- N $^{\circ} .2$ & $\begin{array}{c}\text { Dezembro } \\
2016\end{array}$ & pp. 103-117 \\
\hline
\end{tabular}


desiguais ${ }^{38}$. Mais evidente ainda é a discussão iniciada por Hegel sobre o casamento e a ultrapassagem da unidade exterior dos sexos que podemos encontrar na natureza e o início da compreensão da sua finalidade nas formas do amor consciente ${ }^{39}$.

Talvez Marx soubesse dessa ressalva metodológica, situada na filosofia do direito de Hegel uma vez que este precisa investigar a filosofia do direito já assumindo o despertar da natureza na forma do espírito e o nascimento do tempo - mas o fato de que este lapso apareça n'O capital sem as devidas explicações acaba por produzir na obra uma forma antinatural do trabalho em oposição à supernaturalidade ou sobrenaturalidade do espírito que encontramos na Enciclopédia hegeliana. Segundo Wolff ${ }^{40}$, essa antinaturalidade do pensamento marxiano produz uma forma de dualidade que é ao mesmo tempo objetiva, porquanto indica na história humana sua diferença para com o mundo natural, e metodológica, uma vez que a humanidade e a natureza, em sua distinção, exigem a produção de instrumentos não naturais para o conhecimento da especificidade do homem.

Tentamos mostrar, brevemente, que esse tipo de leitura marxiana deriva de uma apropriação da filosofia do direito de Hegel na qual devemos ter algum cuidado para não concluir no interior do pensamento de Hegel um princípio antrópico ingênuo.

Perder de vista a importância da filosofia da natureza na sistematicidade constituída por Hegel é dar um passo que nos coloca ante a proximidade com as pressuposições da filosofia transcendental de Kant $^{41}$ e Husserl ${ }^{42}$. Assim, sob o aspecto de uma teoria sistemática, como nos alerta Hösle, a filosofia da natureza de Hegel ocupa em seu sistema um lugar central no qual "o espírito é essencialmente mediado pela natureza” e reciprocamente “várias discussões no âmbito da filosofia do espírito são tão pouco compreensíveis sem o recurso à filosofia da natureza quanto a própria filosofia da natureza sem conhecimentos da lógica” ${ }^{43}$.

Como vimos em Hegel, não se trata de retirar do espírito suas raízes naturais, tampouco supor um dualismo de propriedade, encontrando nele algo que não existe no mundo natural, mas de uma atuação cônscia do que já se encontra em operação no mundo orgânico, não se tratando de uma causação, mas de uma circularidade na qual o natural é o espiritual alienado de si e o espiritual é o natural consciente de si. O ganho na passagem de um para o outro não se encontra justificado na adição de um elemento que não se

\footnotetext{
${ }^{38}$ HEGEL, G.W.F. Princípios da filosofia do direito. São Paulo: Martins Fontes, 1997, p. 179.

${ }^{39}$ HEGEL, G.W.F. Princípios da filosofia do direito. São Paulo: Martins Fontes, 1997, p. 150.

${ }^{40}$ WOLFF, F. Nossa humanidade: Aristóteles e as neurociências. São Paulo: Unesp, 2012.

${ }^{41}$ Cf. KANT, I. Crítica da Razão Pura. $5^{\circ}$ Ed. Edição da Fundação Calouste Gulbenkian: Lisboa, 2001. (A 444 B 472, A 445 B 473) sobre as antinomias da razão pura, sobretudo o terceiro conflito das ideias transcendentais a respeito da discussão entre o princípio de imutabilidade e liberdade da natureza.

42 Cf. DERRIDA, J. Introduction. In: HUSSERL, E. L'origine de la géométrie. Paris: Presses Universitaire de France, 1962, p. 98 a distinção, em Husserl, entre Körper (corps) e Leib (chair).

${ }^{43}$ HÖSLE, V. O Sistema de Hegel. São Paulo: Edições Loyola, 2007, p. 312.
}

\begin{tabular}{|c|c|l|l|c|c|}
\hline Intuitio & $\begin{array}{c}\text { ISSN } \\
1983-4012\end{array}$ & Porto Alegre & Vol.9- No.2 & $\begin{array}{c}\text { Dezembro } \\
2016\end{array}$ & pp. 103-117 \\
\hline
\end{tabular}


encontra presente no outro, mas na realização da circularidade autoreflexiva capaz de reconhecer-se como um agente de uma história e de seus momentos infraestruturais.

\section{Referências}

BIMBENET, E. L'animal que je ne suis plus. Paris: Gallimar, 2011.

DERRIDA, J. Introduction. In: HUSSERL, E. L'origine de la géométrie. Paris: Presses Universitaire de France, 1962.

ENGELS, F. Dialectique de la nature. Paris: Édition sociale, 1968.

HÖSLE, V. O Sistema de Hegel. São Paulo: Edições Loyola, 2007.

HEGEL, G.W.F. Enciclopédia das ciências filosóficas, v. II. A filosofia da natureza. São Paulo: Edições Loyola, 1997. . Princípios da filosofia do direito. São Paulo: Martins Fontes, 1997. Fenomenologia do espírito. Rio de Janeiro: Editora Vozes, 2002.

HEIDEGGER, M. Fundamental concepts of metaphysics: world, finitude, solitude. Indiana: Indiana University Press, 1995.

KANT, I. Crítica da Razão Pura. 5a Ed. Edição da Fundação Calouste Gulbenkian: Lisboa, 2001.

MACHEREY, P. In a materialist way. In: MONTEFIORE, A. (org). Philosophy in France today. New York: Cambridge University Press, 1987.

MARX, K. O capital - volume I. trad. Rubens Enderle. São Paulo: Boitempo, 2013.

MERLEAU-PONTY, M. Conversas - 1948. São Paulo: Martins Fontes, 2004. A estrutura do comportamento. São Paulo: Martins Fontes, 2006.

SAFATLE, V. Circuito dos afetos: corpos políticos, desamparo e o fim do indivíduo. São Paulo: Cosac Naify, 2015.

WOLFF, F. Nossa humanidade: Aristóteles e as neurociências. São Paulo: Unesp, 2012.

Recebido em: 23 de agosto de 2016.

Aprovado para a publicação em: 17 de novembro de 2016.

\begin{tabular}{|c|c|l|l|c|c|}
\hline Intuitio & $\begin{array}{c}\text { ISSN } \\
1983-4012\end{array}$ & Porto Alegre & Vol.9- N $^{\circ} .2$ & $\begin{array}{c}\text { Dezembro } \\
2016\end{array}$ & pp. 103-117 \\
\hline
\end{tabular}

